\title{
Original Article \\ Short Term Outcome of Urethroplasty with or without Urethral Stent: A Comparative Study
}

\author{
Karim SMR ${ }^{1}$, Abdullah $\mathrm{SM}^{2}$, Shaha $\mathrm{BK}^{3}$, Rahman $\mathrm{MM}^{4}$, Amin $\mathrm{MR}^{5}$
}

\begin{abstract}
Urethroplasty is the surgery for Hypospadias. The most common complication of Hypospadias surgery is urethro-cutaneous (U-C) fistula. We designed this study to compare the short term outcome of Urethroplasty with or without urethral stent postoperatively. A total 30 patients of distal penile hypospadias except glnular variety have been studied prospectively in Pediatric Surgery Department of Banga Bandhu Sheikh Mujib Medical University, Dhaka for a period of 20 months, from March 2005 to October 2006. All patients were divided into Group-A (pt with stent) and Group$B$ (pts without stent). Age ranges of all patients were 2-12 years. After operation no patient developed urinary retention in stented group (Group-A) and 3 patients developed urinary retention which was managed by suprapubic puncture. 5 patients developed urethra-cutaneous fistula in stented group (Group-A) and 2 patients developed fistula in non stented group (Group-B). Calibration was done in all patients after 2 weeks of operation. Before calibration 2 patients came to us with narrow urinary stream of Group-B. After analyzing the result, it was concluded that the short term outcome of Urethroplasty without postoperative urethral stent is better than with stent specially in terms of Urethro-cutaneous fistula.
\end{abstract}

\section{Introduction}

The term 'Hypospadias' is derived from Greek language and refers to a rent (spadon) on the ventrum of the penis ${ }^{1}$. Hypospadias is a developmental anomaly characterized by a urethral meatus that opens onto the ventral surface of the penis, proximal to the end of the glans. The meatus may be located anywhere along the shaft of the penis from the glans to the scrotum or even in the perineum ${ }^{2}$.

1. Corresponding Author: Dr. S M Rezaul Karim, MBBS, MS Assistant Professor, Department of Pediatric Surgery North East Medical College, Sylhet

2. Dr. Sheikh Md Abdullah, MBBS, MCPS, MS Junior Consultant, Surgery Feni Shadar Hospital, Feni

3. Dr. Bablu Kumar Shaha, MBBS, MS Assistant Professor, Department of Pediatric Surgery Rangpur Medical College, Rangpur

4. Professor Dr. Md Matiur Rahman, MBBS, FCPS Department of Pediatric Surgery Bangabandhu Sheikh Mujib Medical University, Dhaka

5. Professor Dr. Md Ruhul Amin, MCPS, FCPS, MS Professor of Department of Pediatric Surgery Bangabandhu Sheikh Mujib Medical University, Dhaka
Hypospadias is the result of failure of fusion of the urethral folds on the ventral aspect of the penis. It occurs in approximately 3.2 per 1000 male live births or 1 in every 300 male children ${ }^{3}$. Hypospadias may be manifested classically as an association of three anatomical anomalies of the penis. (1) an abnormal ventral opening of the urethral meatus which can be located any where on the ventral aspect of the penis or in the perineum, (2) an abnormal ventral curvature of the penis (Chordee) and (3) an abnormal distribution of the foreskin around the glans with the ventrally deficient hooded foreskin ${ }^{2}$.

Hypospadias is a grievous deformity, which must ever move us to the highest surgical endeavor. Hypospadias surgery is both an art and science, and the fact that over 200 different types of repair have been reported in the literature confirms that it is difficult surgery with many complications and frequently inadequate cosmetic and functional results ${ }^{4}$.

The type and incidence of complications vary with the particular form of hypospadias and its repair. Urethrocutaneous fistula is the most commonly reported complication of hypospadias surgery; currently an expected fistula formation of 10 to 15 percent exists for one stage hypospadias surgery ${ }^{1}$.

Inherent to all hypospadias repair has been the use of a bladder drainage catheter or a stent, the purpose of which has been to provide temporary urinary diversion, immobilize the suture line, drain the neourethra and reduce retraction of neourethral caliber. On the other hand, disadvantage of catheter drainage or stenting include the length of hospital stay (4-8 days), decreased patient mobility, bladder spasm and increased potential for infection. Other complications include migration into the bladder and mechanical catheter problems that may create inadequate drainage and even results in pressure ischemia of the neourethra ${ }^{5}$.

Rabinowitz in 1987, reported outpatient catheterless Mathieu repair for distal penile hypospadias with an excellent cosmetic, functional outcome and fewer complications ${ }^{5}$. He concluded that urinary diversion was unnecessary. Hadidi in 2003 concluded that the incidence of complications in the form of failure of repair, fistula formation, or meatal stenosis was higher in-group with stenting $(10 \%)$ than in-group without stenting $(2 \%)$. One study showed that the urethral stent may be associated with significant morbidity without confirming any advantage in postoperative course or the final results (Wheeler 1993). Hakim in 1996, have shown no difference in outcome with or without use of stent ${ }^{6}$. Buson in 1994, have shown that fistula formation is less with use of stent ${ }^{7}$.

Our present study is to compare the short-term results of urethroplasty in coronal and distal penile shaft variety of anterior hypospadias, performed by Mathieu technique with 
or without urethral stent. As far I know, such type of study was not performed in our country. So I was interested to do this study.

\section{Materials And Methods}

This study was carried out in the Department of Paediatric Surgery, Bangabandhu Sheikh Mujib Medical University, Dhaka. It was a randomized control trial study conducted in patients admitted in Paediatric Surgery Department and was carried out from March 2005 to October 2006 a period of 20 months. Patients admitted with coronal and distal penile shaft variety of hypospadias were included.

During selection of patient inclusion Criteria was 1) all patients within the age range of 2 to 12 years and 2) coronal and distal penile shaft variety hypospadias with or without mild chordee. The exclusion criteria was 1) Patients with previous $\mathrm{H} / \mathrm{O}$ urethroplasty or any other penile surgery. Sampling technique was purposive sampling. Total 30 patients with coronal and distal penile shaft variety of hypospadias were included in this study and divided them into two groups on the basis of postoperative urethral stent, Group-A and Group-B. 15 patients were in Group-A with urethral stent and 15 patients were in Group-B without urethral stent

Patients after admission who fulfilled the inclusion criteria of the study were entitled for this study. Necessary information regarding the study was taken from the attendants. Written informed consent was taken from the guardians to include them in this study. After preoperative assessment and necessary investigations in all the patients. Urethroplasty was done in all cases using Mathieu procedure.

In half of the patient (15 patients), plastic urethral stent (BMI feeding tube) was kept in situ postoperatively and in other half of the patient (15 patient) stent was removed just after completion of operation and remain it unstented. Post operative follow up was given accordingly.

\section{Results}

\section{Age Distribution}

Table 1 showed age range of Group-A was 2 to 12 years and Group-B was 2 to 11 years. The mean age of Group-A was $6.43+3.37$ and Group-B was $6.43+6.43$. P value of two age group was 0.828 , which is statistically non significant.

Table I. Comparison of age between study groups

\begin{tabular}{llll}
\hline Age (years) & Group A & Group B & P value \\
\hline & $(\mathrm{n}=15)$ & $(\mathrm{n}=15)$ & \\
Mean \pm SD & $6.70 \pm 3.73$ & $6.43 \pm 6.43$ & $0.828 \mathrm{~ns}$ \\
Range & 212 & 211 & \\
\hline
\end{tabular}

Group A : Urethroplasty with urethral stent

Group B : Urethroplasty without urethral stent

Unpaired Student's't' test

$\mathrm{ns}=$ Not significant

\section{Type of Hypospadias}

Table 2 showed coronal and distal penile shaft variety of anterior hypospadias was included in the study. In group-A, 7 $(46.7 \%)$ patients were with distal penile shaft variety and another $8(53.3 \%)$ patients were coronal variety.

In group-B, $8(53.3 \%)$ patients were with distal penile shaft variety and other $7(46.7 \%)$ were with coronal variety of hypospadias.

$\mathrm{P}$ value is 1.00 , which is statistically non significant.

Table II. Distribution of type of hypospadias

\begin{tabular}{llll}
\hline Hypospadias & Group A & Group B & P value \\
\hline & $(\mathrm{n}=15)$ & $(\mathrm{n}=15)$ & \\
& No. $(\%)$ & No. $(\%)$ & \\
\hline Coronal & $8(53.3)$ & $7(46.7)$ & $1.000 \mathrm{~ns}$ \\
Distal penile shaft & $7(46.7)$ & $8(53.3)$ & \\
\hline
\end{tabular}

Chi-Square test with Yates correction

ns $=$ Not significant

\section{Presence or absence of chordee}

Table 3 showed among the Group-B 4 (26.7\%) patients were with mild chordee and $11(73.3 \%)$ were without chordee. Among the Group-A 5 (33.3\%) patients were with chordee and $10(66.7 \%)$ were without chordee. $\mathrm{P}$ value is 1.00 , which is statistically non significant.

Table III. Status of chordee before urethroplasty

\begin{tabular}{llll}
\hline Chordee & Group A & Group B & P value \\
\hline & $(\mathrm{n}=15)$ & $(\mathrm{n}=15)$ & \\
& No. $(\%)$ & No. $(\%)$ & \\
\hline Absent & $10(66.7)$ & $11(73.3)$ & $1.000 \mathrm{~ns}$ \\
Present & $5(33.3)$ & $4(26.7)$ & \\
\hline
\end{tabular}

Chi-Square test with Yates correction ns $=$ Not significant

Urethro-cutaneous fistula development after urethroplasty:

Table 4 showed in group-A, 5 (33.3\%) patients developed Urethrocutaenous fistula and $10(66.7 \%)$ patient did not developed fistula. In group-B, $2(13.3 \%)$ patients developed urethrocutaneous fistula $13(86.7 \%)$ patients did not develop fistula. $\mathrm{P}$ value is 0.388 , which is statistically non significant.

Table IV. Occurrence of urethrocutaneous fistula after urethroplasty

\begin{tabular}{llll}
\hline $\begin{array}{l}\text { Urethrocutaneous } \\
\text { fistula }\end{array}$ & $\begin{array}{l}\text { Group A } \\
(\mathrm{n}=15)\end{array}$ & $\begin{array}{l}\text { Group B } \\
(\mathrm{n}=15)\end{array}$ & Pvalue \\
& No. $(\%)$ & No. $(\%)$ & \\
\hline Yes & $5(33.3)$ & $2(13.3)$ & $0.388 \mathrm{~ns}$ \\
No & $10(66.7)$ & $13(86.7)$ & \\
\hline
\end{tabular}

Chi-Square test with Yates correction ns $=$ Not significant

Urinary stream after urethroplasty:

Table 5 showed in group-A, 2 (13.3\%) patients came to us 2012 Volume 24 Number 01

MEDICINE Today 
with narrow stream before calibration and $13(86.7 \%)$ patients urinary stream was normal before calibration. In group-B 4 (26.7\%) patients came to us with narrow stream and 11 $(73.3 \%)$ with normal stream before calibration. All patients were advised for starting calibration with age related urethral dilator after 2 weeks of urethroplasty. $\mathrm{P}$ value is 0.648 , which is statistically non significant.

Table V. Quality of urinary stream after urethroplasty

\begin{tabular}{llll}
\hline Urinary & Group A & Group B & P value \\
\hline stream & $(\mathrm{n}=15)$ & $(\mathrm{n}=15)$ & \\
No. $(\%)$ & No. $(\%)$ & & \\
\hline Normal & $13(86.7)$ & $11(73.3)$ & $0.648 \mathrm{~ns}$ \\
Narrow & $2(13.3)$ & $4(26.7)$ & \\
\hline
\end{tabular}

Chi-Square test with Yates correction ns $=$ Not significant

\section{Discussion}

The present study has been designed to compare the short-term outcome of urethroplasty in terms of occurrence of common complications between urethroplasty with and without urethral stent in anterior hypospadias by Mathieu procedure. 30 patients were included in the study, of them urethroplasty was done with urethral stent in 15 patients and without stent in other 15 patients. Result was analyzed.

In this study age of the patients were 2 to 12 years. The mean (+ SD) age of Group-A was $6.43+3.37$ and Group-B was 6.43 +6.43 . There is no significant difference between mean ages of two groups. In 1975, an ad hoc committee of the American Academy of Pediatrics, composed of Urologist and Pediatricians, concluded that the optimal time for surgery from a psychological perspective, was during the 4th to 5th year of life ${ }^{8}$. From this data, it is evident that the mean age of urethroplasty in our country is higher. Coronal and distal penile shaft variety of anterior hypospadias was included. In Group-A, $53.3 \%$ were coronal and $46.7 \%$ were distal penile shaft variety hypospadias and in Group-B, $46.7 \%$ were coronal and $53.3 \%$ were distal penile shaft variety hypospadias. There is no significant difference between two groups. 5 patients $(33.3 \%)$ in Group-A and 6 patients (40.0\%) in Group-B had narrow meatal opening preoperatively. Patients with narrow meatus were almost homogenously distributed between two groups. Minimum chordee was present in 4 patients $(26.7 \%)$ in Group-A and 5 patients (33.3\%) in Group-B. Retik (1994) reported that 100 percent patients of scrotal or perineal hypospadias has severe chordee of that study. In this study only anterior variety of hypospadias were included and mild chordee was almost homogenously distributed in two groups ${ }^{9}$.

After preoperative evaluation, urethroplasty was done in all 30 patients by Mathieu procedure. In 15 patients plastic urethral stent (BMI feeding tube) was given and in other 15 patients stent was not given. In Group-A patients, stent was removed at $7^{\text {th }}$ postoperative day. Snodgrass (1996) recommended urinary diversion for 2 to 14 days.

All the patients after urethroplasty, we followed up every day postoperatively and after discharge at 2 nd week and at after 4 weeks of operations.

In this study 5 patients $(33.3 \%)$ in Group-A and 2 patients $(13.3 \%)$ in Group-B developed urethrocutaneous fistula. In the stented group, the fistulas were evident on the day of stent removal in 2 cases and on the day after stent removal in 3 cases and in non-stented group one fistula evident on $6^{\text {th }}$ postoperative day and another on $7^{\text {th }}$ postoperative day. There is no specific established data on the occurrence of Urethro-cutaneous fistula after urethroplasty in our country. In Dhaka Shishu Hospital (BICH), Dhaka, urethrocutaneous fistula after headed the list of complications in studies; 40 percent $^{10} 34.4$ percent $^{11}$ and in BSMMU, Dhaka, 33.3 percent ${ }^{12}$. Which is consistent with my study in urethroplasty with stent.

In this study it is also evident that fistula in the stented group is much higher than non stented group. It may be due to pressure ischemia or continuous irritation of suture line by stent. Hadidi (2003) reported $10 \%$ fistula in stented group an $2 \%$ in non-stented group ${ }^{13}$. Narrow urinary stream developed in 2 patients (13.3\%) in Group-A and 4 patients $(26.7 \%)$ in Group- B. There is no significant difference between two group. Age related ureteral dilator was introduced to confirm the apparent stenosis and could not pass easily. Calibration was started after 2 weeks of operation. The meatus of a boy under 1 year of age should accept a 5 Fr. Urethral calibrator (Dilator), between 1to 3 years of age below 8 Fr. 4 to 10 years 8 Fr. And 11 to 12 years $10 \mathrm{Fr}^{14,15}$.

Urethro-cutaneous fistula is the most alarming complication of hypospadias repair. From this study, it seems that their number is less in the proposed technique of no stent in anterior hypospadias urethroplasty and henceforth better than using a stent. But for definitive comment a large series is needed.

\section{References}

1. Duckett JW, Baskin LS. Hypospadias. In: O`Neill JA, Rowe MI, Grosfield JA, Fankalsrud EW, Coran AG(ed) Paediatric Surgery, 5th edn, Mosby Year book, St.Louis, Missouri. 1998;2:1761-177.

2. Murphy JP. Hypospadia. In: Ashcraft KW, Holcomb GN, Murphy JP (ed), paediatric Surgery, 4nd edn, W.B. Saunders company, Philadelphia. 2005;807-825.

3. Sweet RA, Schrott HG, Kurland R \&Culp OS. Study of the incidence of hypospadias in Rochester, Minnesota, 1940-1970, and a case control comparison of possible etiologic factors, Mayo Clin Proc.1974;49:52-8.

4. Duckett JW, Kaplan GW \& Woodard JR. Panel: Complications of hypospadias repair. Urol Clin N Am.1980:443-52.

5. Rabinowitz, R. Out patient catheter less modified Mathieu hypospadias repair. J. Urol. 1987;138:1074-7.

6. Hakim S, Merguerian PA, Rabinowwitz R. Outcome analysis of the modified Mathieu hypospadias repair: 
comparison of stented and unstented repair. J Urol.1996;156:836.

7. Buson H, Smiley D, Reiberg. Distal hypospadias repair without stent, is it better? J Urol. 1994;151:1059-61.

8. Retik $\mathrm{AB}$ \& Borer JG. Hypospadias. In: Retik AB, Walsh PC, Darracott E \&ED Vaughan, Campbells Urology, 8th edn, WB Saunders Company, Philadelphia. 2002;2284-2323.

9. Retik AB, Bauer SB, Mandell J, Management of severe hypospadias with a two stage repair. J Urol. 1994;152:749-751.

10. Sajid, MM. Comparison between the outcome of tunica vaginalis blanket wrap and non wrap procedures in urethroplasty. MS Thesis, BSMMU, Dhaka. 2005;13.

11. Masud AKMM. Hypospadias surgery: A short term outcome, MS thesis, University of Dhaka, 2000.
12. Alam MS. Comparison of single stage correction of distal and mid penile hypospadias by V.T. Joseph's technique and onlay Island flap techniqur. MS Thesis, BSMMU, Dhaka.

13. Hadidi AT, Abdaal N \& Kaddah S 2003. Hypospadias repair: is stenting important ? Kasar el. Aini J Ssurg. 1998.

14. Azmy AF. General Principles. In: Hadidi AT \& Azmi AF (ed), Hypospadias Surgery, Springer company, Verlag berlin. 2004;87-88.

15. Anderson GF. Urinary tract obstruction. In: $M M$ Ziegler, RG Azizkhan, \& TR Weber (ed), Operative pediatric Surgery, Mc Graw- Hill Companies, United States of America. 2003;871-85. 